\title{
Tsunami detection system using unusual animal behavior- A specified approach
}

\author{
A. N. Meenakshi, B. I. Juvanna \\ Hindustan Institute of Technology and Science, Padur, Chennai
}

Email address:

abu221985@gmail.com (A. N. Meenakshi),juvanna@gmail.com (B. I. Juvanna)

To cite this article:

A. N. Meenakshi, B. I. Juvanna. Tsunami Detection System Using Unusual Animal Behavior- A Specified Approach, Earth Science. Vol. 2, No. 1, 2013, pp. 9-13. doi: 10.11648/j.earth.20130201.12

\begin{abstract}
Now a days Tsunami is occurring very frequently in all over the word. So it is essential to predict it very earlier before the arrival of Tsunami in order to save many lives. The earthquake can be predicted in three different terms: short- term, intermediate-term, and the long-term. The two major methods of prediction are Geophysical precursors and the unusual animal behavior. This paper focus on the unusual animal behavior by monitoring behavior of the animal for predicting the Tsunami by analyzing the sensory organs of animals which were able to monitor, and sense, stimuli preceding an earthquake.
\end{abstract}

Keywords: Electromagneticfields, Geophysical Precursors, Tsunami, Vibrations

\section{Introduction}

Animals are sensitive to weak signals which are often unnoticed even by the delicate instruments and measuring techniques. To predict the earthquake the responses from the animal and the signal vibration is going to be proposed here. The data collection and processing method is a mixed signal processing model of different types of signal analyzing techniques. This incorporated processing increases the efficiency by mathematical analysis method. If there is any changes in the environment the animals react to them and their reaction. This response from the animal will be pheromone secretions and homoeostasis rate variations An earthquake induces such changes to highly sensitive species.Many species naturally have senses that are far more accurate than those possessed by humans, it seems less strange!

Normally the animals will have the power to smell, hear and the ability to sense the minute vibrations. Most of the animals will use the electromagnetic field to navigate from one place to another and for finding the prey.

Some animals use the earth's geomagnetic field to get adjust themselves and moves through their environment. The small organisms use the method of magnetotactic bacteria.

\section{Biological Similarity}

As per the Kleiber's law, the homeostatis rate decreases proportionally to the increase in mass.

The smaller sized animals comparatively produce more chemicals than bigger sized animals.

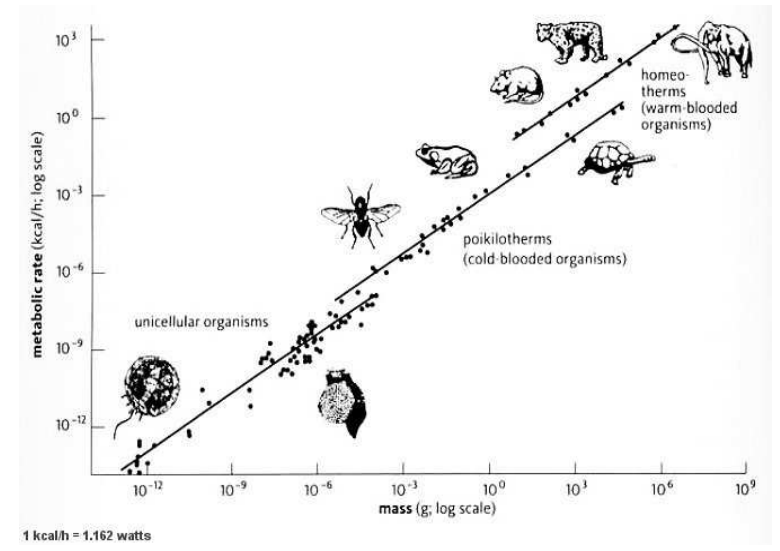

Fig. 1. The figure illustrates the distribution.

$\mathrm{E}$ is the outcome of energy in the earth quake.Let two different animals- smaller one with body radius $r$, and larger one with $R$. so, $\mathrm{E}=$ Work done by the animals in earth quake.

So, Work done

$(\mathrm{W})=\mathrm{E}=$ Force $(\mathrm{F}) *$ Distance

$\mathrm{F} 1=\mathrm{W} / \mathrm{r} ; \mathrm{F} 2=\mathrm{W} / \mathrm{R}$;

It is found $: F 1>F 2$

Force on smaller body is greater and moment is greater for same earthquake energy.

The weak signals cant be recognized by the huge animals all that signals will be noticed the small animals. The small 
animals produces some chemical changes in their body that has to be carefully noticed at the time of earth quake occurs to get the information from the epicenter.

\section{How Do Animal Sense?}

The animals can sense by the

\section{A. Mechanical Reception}

In animals the magnetite is used as the magnetic particle. The usage of magnetite has shown in the magnetotactic bacteria which will be rotated by the magnetic field .

\section{$B$.Electric Induction}

Movement in a magnetic field will result in an induced electric field. The some kind of fish have the sensory organ to perceive the electric field and use the organ to detect the magnetic field.

\section{Energy Circulation}

The shape of the earth is sphere. So a sphere, initially at a uniform temperature $T_{0}$ is suddenly placed in a fluid medium whose temperature is maintained constant at a value $\mathrm{T}_{1}$. The heat-transfer coefficient between the medium and the sphere is constant at a value $h$. The sphere is isotropic, and the temperature variation of the physical properties of the material forming the sphere may be neglected. Derive the equation relating the temperature of the sphere to the radius $r$ and time $t$.

For unsteady-state one-dimensional heat conduction: According to the Laplace transform the heat conduction can be given as

$$
\frac{\partial T}{\partial t}=\alpha \frac{\partial^{2} T}{\partial x^{2}}
$$

Boundary condition:

$$
\begin{array}{ll}
T=T_{0} & \text { at } t=0 \\
T=T_{1} & \text { at } x=0
\end{array}
$$

The heat concentrated at the surface initially is $\mathrm{T}=0$ at $\mathrm{t}=0, \mathrm{x}>0$

$\mathrm{H}=$ constant

The heat is supplied at fixed rate is

$$
\begin{aligned}
& T=0 \quad \text { at } t=0, x>0 \\
& Q=-k \frac{\partial T}{\partial x} \quad \text { at } x=0
\end{aligned}
$$

The energy flow in earthquake can be thus compared to a distribution of the Bessel's function.

As per the Bessels function of second kind

For non-integer $\alpha, Y_{\alpha}(x)$ is related to $J_{\alpha}(x)$ by:

$$
\mathrm{Y}_{\alpha}(\mathrm{x})=\left(\mathrm{J}_{\alpha}(\mathrm{x}) \cos (\alpha \pi)-\mathrm{J}_{-\alpha}(\mathrm{x})\right) / \sin (\alpha \pi)
$$

In the case of integer order $n$, the function is defined by taking the limit as a non-integer $\alpha$ tends to $n$ :

$$
\begin{aligned}
& \mathrm{Y}_{\mathrm{n}}(\mathrm{x})=\lim \mathrm{Y}_{\alpha}(\mathrm{x}) \\
& \alpha \rightarrow \mathrm{n}
\end{aligned}
$$

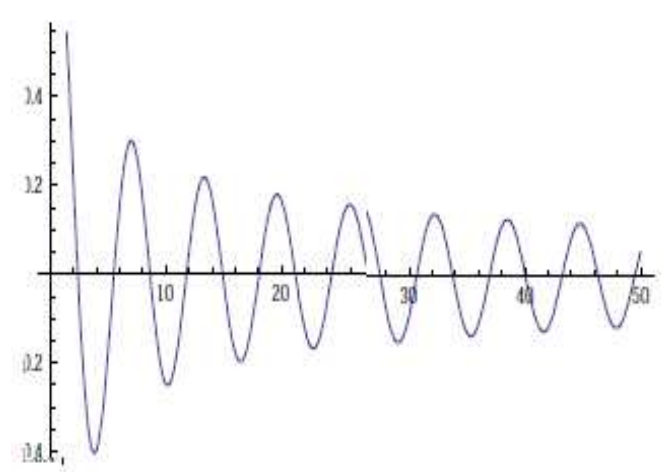

Fig. 2. Animal Response.

The maximum points for gradient zero are derived and list plotted on graph animals Response at the Time of Earth Quake.Animals are sensitive to stimulus. In certain cases it outreaches Human precision .The following graph shows the estimated "Frequency ratio"(ratio of total number) of animals reacting to earthquake at different distances from epicentre. The distances are in kilometres.

\section{Table}

The table shows the approximate proportion of animals reacting to earthquake at different instances from epicentre.

Table 1. Animal Response.

\begin{tabular}{ll}
\hline Approximate distance & $\begin{array}{l}\text { Approximate frequency distribution } \\
\text { of animal reaction }\end{array}$ \\
\hline Epicenter & 39 \\
$20-50 \mathrm{~km}$ & 26 \\
$70-100 \mathrm{~km}$ & 21 \\
$150-200 \mathrm{~km}$ & 15 \\
Greater than $250 \mathrm{~km}$ & 6 \\
\hline
\end{tabular}

The graphical representation of the above data is shown in a two dimensional graph with the vertical axis for approximate frequency distribution of animals reacting; the horizontal axis shows the approximate distance from epicentre. The curve is approximate and data collected from many sources .The curve is similar to a energy distribution system with decreasing energy. The similarity is further compared in later sections.

Long before the occurrence of a shock, the Earth's electric field is dominated by long wavelengths, with periods greater than $24 \mathrm{~h}$, superimposed on random, high frequency noise. As we move towards the time of occurrence of the event, a characteristic oscillation of the electric field with a $24 \mathrm{~h}$ period builds up and is superimposed on the previous long wavelengths. 
A few days prior to the occurrence of the earthquake, this $24 \mathrm{~h}$ period oscillation increases in amplitude, nearly exponentially, until the earthquake begins, when a decrease in the amplitude of the oscillation is observed. some authors studied recordings can be concluded that the $24 \mathrm{~h}$ period oscillation of the Earth's electric field observed is associated to a high degree with the dynamic conditions in the focal area prior to the occurrence of the shock .

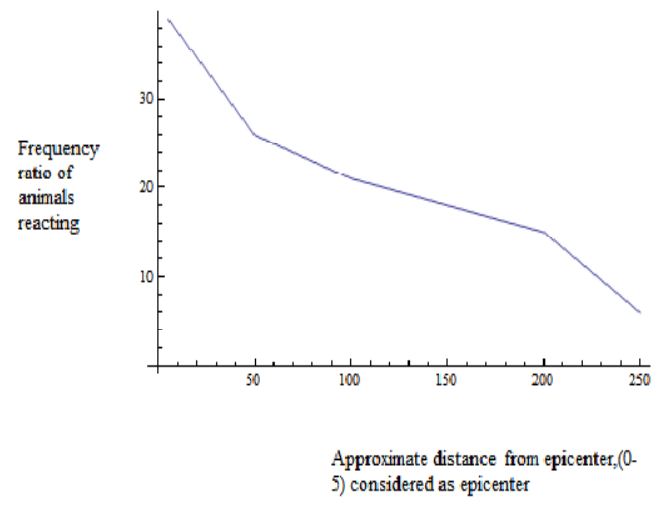

Fig. 3. Frequency distribution verses epicenter distance.

\section{Animal Behaviour- A Survey}

In 1920, the largest earthquake to hit China with a magnitude of 8.5 occurred in Haiyuan County, Ninghsia Province. According to reports of eyewitnesses, prior to this earthquake, wolves were seen running around in packs, dogs were barking unusually, and sparrows were flying around wildly.

It is reported that prior to the 6.8 magnitude earthquake in 1966 in Hsingtai County, Hopei Province, in Northern China, all the dogs at a village near the epicenter had deserted their kennels and thus survived the disaster.

Prior to the earthquake of July 18, 1969, (magnitude 7.4) in the Pohai Sea, unusual behavior was observed in seagulls, sharks, and five different species of fish. Based on observations of unusual behavior of giant pandas, deer, yaks, loaches, tigers and other animals, a warning was issued at the Tientsin People's Park Zoo, two hours before the earthquake struck.

The Chinese began to study systematically the unusual animal behavior, and the Haicheng earthquake of February 1975 was predicted successfully as early as in mid- December of 1974. The most unusual circumstance of animal behavior was that of snakes that came out of hibernation and froze on the surface of the earth. Also a group of rats appeared. These events were succeeded by a swarm of earthquakes at the end of December 1974.

During the following month, in January 1975, thousands of reports of unusual animal behavior were received from the general area. Local people saw hibernating snakes coming out from their holes and into the snow. In the first three days in February the activity intensified even more and unusual behavior of the larger animals such as cows, horses, dogs and pigs was reported. On February 4, 1975, an earthquake of magnitude 7.3 struck the Haicheng County, Liaoning Province.

More instances of unusual animal behavior were reported.

A stock breeder in northern China, feeding his animals before dawn on July 28, 1976, in the area of the Kaokechuang People's Commune, approximately 40 kilometers away from the city of Tangshan, reported that his horses and mules instead of eating were jumping and kicking until they finally broke loose and ran outside. A few seconds later, a dazzling white flash illuminated the sky. Tremendous rumbling noises were heard as a 7.8 magnitude earthquake struck the Tangshan area.

\subsection{Studies of Animal Behavior}

Throughout China's long history, unusual behavior has been observed in every kind of common animal. Most of the behavior falls into the category of unusual restlessness and disorientation.

The principal focus of research work in China has been on the behavior of pigeons. Biological studies on pigeons determined that a hundred tiny units exist between the tibia and fibula on a pigeon's leg. These nerve units are connected to the nerve center, and are very sensitive to vibrations. Scientists determined that prior to an earthquake of magnitude 4.0, which occurred in the area of the study, fifty pigeons that had severed connections between the tibia, fibula, and the nerve centers, remained calm before the earthquake, while those with normal connections became startled and flew away.

Because of the success in monitoring unusual animal behavior for the prediction of certain earthquakes, the Chinese, who have pioneered this work, have looked into ways to construct instruments that would duplicate the sensory organs of animals which were able to monitor, and sense, stimuli preceding an earthquake.

\subsection{Mechanisms of Animal Responses}

The behavior of an animal might be subject to changes in the magnetic field preceding a major earthquake and such changes may be sensed by energy transfer at the electron level which, in turn, cause changes in the cellular behavior, or response. The living cell is essentially an electrical device and a micro molecular structure, and the sensory organs are all interconnected. Electromechanic changes occurring prior to the occurrence of a large earthquake may be sensed by certain animals and filtered, then instinctively interpreted. Thus animals may have the means and sensitivity to sort out and discriminate the threatening precursory signals of an impending earthquake, thus activating a behavior pattern for survival.

These precursory electromagnetic or electro mechanic changes which precede an earthquake, although mixed with background noise, must be filtered by animals and coordi- 
nated through their sensory response to the total environment. Thus, behavior is determined by the sensitivity of the different component parts of the living system to the surrounding medium. Experiments with new instruments and electronic solid state sensors are being used now to determine animal response to impending catastrophic occurrences. The benefit from such research would be in duplicating the sensory responses of animals to construct equally responsive instruments that can record or monitor these precursory changes. Thus, observing and studying animal behavior could lead to better earthquake prediction instrumentation.

\subsubsection{Dogs and Cats}

Cats and dogs react to natural disasters with anti social behavior. Heading the study called the "Animal Earthquake Project," expert David Jay Brown continues to explore, rationalize and search for the definitive reason for unusual animal behavior before natural disasters. Among findings, Brown reports cats hide, and dogs howl and even bite owners before an earth temblor strikes. Animal behaviorist and author of "The Naked Ape," Desmond Morris says dogs often shiver and shake prior to a thunderstorm. Morris also suggests that because dogs olfactory senses are 10,000 to 100,000 times stronger than humans possess, this may give them the ability to smell a change in the air before storms and earthquakes. Cats reportedly move litters of kittens before the onset of storms and earthquakes.

\subsubsection{Sharks}

Observations report that sharks move to deeper water before a hurricane.Scientists at Mote Marine Laboratory of Sarasota, Florida, documented 14 electronically tagged black tip sharks bolting into deeper waters 12 hours before the 2004 Hurricane Charley pounded Florida's Gulf Coast. Monitored over a four-year period in shallow waters before the unusual behavior, all 14 of the ocean creatures did not return to the sea laboratory for nearly two weeks. The scientists report noticing that the newly observed behavior of the sharks coincided with the abrupt drop in the barometer readings as the hurricane approached landfall.

\subsubsection{Elephants}

Working elephants of Thailand ran to higher ground before the 2005 tsunami devasted shoreland.

According to Turner Network News report after the 2005 tsunami that destroyed much of the Indian Ocean's coastline and killed more than 200,000 people, working elephants trumpeted, broke their chains and ran to higher ground just ahead of the tsunami slamming the coast of Thailand. Two of the runaway animals brought back from their mountain retreat to the work camp cried throughout the night before the tsunami disaster struck the next morning.

\subsubsection{Birds}

Flocks of birds may abandon nests prior to natural disasters. Birds prior to the 2005 Indian Ocean tsunami suddenly abandoned nesting areas before the devastation hit
Thailand.

\section{Mixed Signal Processor}

The data collection process identifies the chemical, sound or electromagnetic signals. The amplified signal is filtered according to type of data. The peak detector checks the threshold of the data. It is further analysed and more methods can be added for further precision. Previous database is used to observe changes in environment and forecast earthquake.

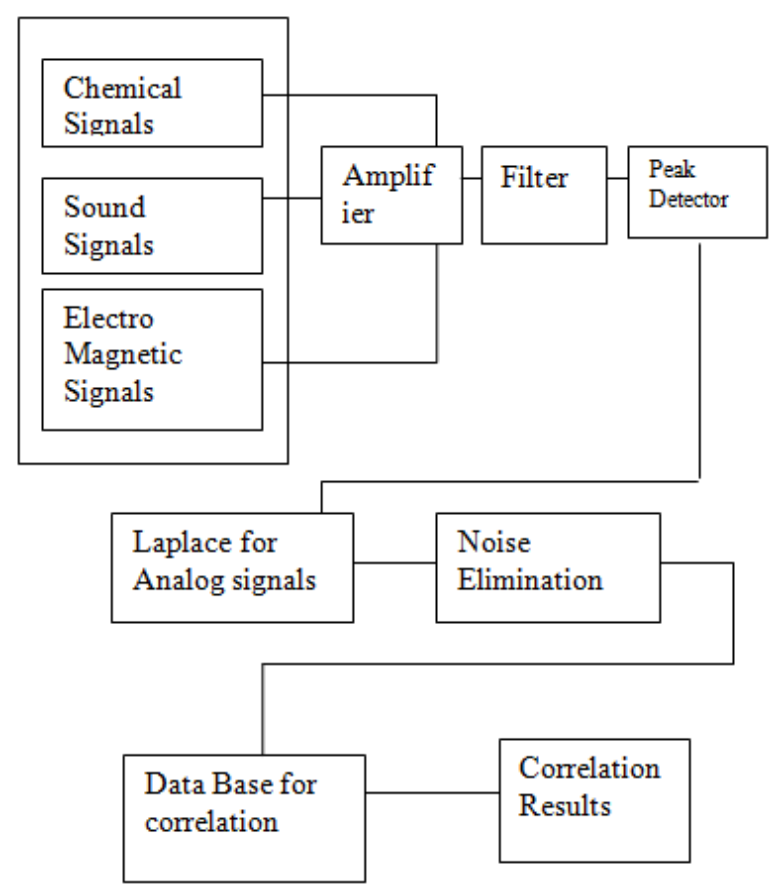

Fig. 4. Mixed signal Processor.

\section{Conclusion}

Our study of animal behaviour has found significant response by animal at large distances from the epicentre. So if the earthquake is predicted during the P-wave or if the earthquake is shifting in a direction this prediction model can be used to predict earthquake at time, $t=$ distance/speed, before the earthquake reaches that area. By the energy circulation model we can easily able to predict the behaviour of the different kinds of animal. The energy is usually in the form of radiation and vibration. Hence the speed of energy is approximately the speed of electromagnetic waves. So if this system allows observing significant animal signals at a long distance, a successful prediction for earthquake is possible.

\section{References}

[1] Joseph L. Kirschvink, "Earthquake Prediction by Animals: Evolution and Sensory Perception.", Bulletin of the Seismological Society of America, 90, 2, pp. 312-323, April 
2000.

[2] Neeti Bhargava , V. K. Katiyar, M. L. Sharma P. Pradhan, "Earthquake Prediction through Animal Behavior: A Review", Indian Journal of Biomechanics: Special Issue (NCBM 7-8 March 2009).

[3] Tristram D. Wyatt, "Pheromones and Animal BehaviourCommunication by Smell and Taste", ISBN-13 978-0-511-07734-0 eBook(Net Library),University of Oxford.

[4] Thomas Breithaupt, Martin Thiel, "Chemical Communication in Crustaceans", Springer New York Dordrecht Heidelberg London. ISBN 978-0-387-77100-7 e-ISBN 978-0-387-77101- 4 DOI 10.1007/978-0-387-77101-4.

[5] Yan Xie, "Chemical Signal Analysis With FOURIER MICROFLUIDICS",Department of Electrical Engineering and Computer Science, CASE WESTERN RESERVE UNIVERSITY August, 2008.

[6] G Pollack and Krahe R, "Signal Identification: Peripheral and Central Mechanisms", Elsevier Ltd., McGill University, Montreal,QC, Canadã ,2009 .

[7] Tyler Carroll ,Rose Colangelo ,Tom Strott, "Bird Call Identifier Identifying Songs of Bird Species through Digital Signal Processing Techniques", Worcester Polytechnic Institute, 29 Apr 2010.

[8] Ll. Parcerisa, "Molecular Communication Options for Long Range Nanonetworks" 2009'Broadband Wireless Networking (BWN) Laboratory, School of Electrical and Computer Engineering, Georgia Institute of Technology, 250 14th Street, Atlanta, GA 30332, USA, September 2008 to July.
[9] Motoji Ikeya, "Earthquakes and animals From folks to legends", World Scientific Publishing Co.Ltd. ISBN 981-238-591-6

[10] "Atmospheric anomalies observed during earthquake occurrences", Geophysical research letters,vol.31,L17110, doi:10.1029/2004GL019865,2004

[11] "Electromagnetic signals from bacterial DNA", arXiv: 1104.3113v1, [physics.bio.-ph], 15april 2011.

[12] Kalmijn, A. J., .The detection of electric fields from inanimate and animate sources other than electric organs., in Handbook of Sensory Physiology, Vol. 9, A. Fessard (Editor), Springer-Verlag, Berlin, New York, 147.200.,1974.

[13] Kirschvink, J. L., .Earthquake Prediction by Animals: Evolution and Sensory Perception., Bulletin of the Seismological Society of America, 90, 2, pp. 312-323, 2000.

[14] Knudsen, E. L., .Spatial aspects of electric fields generated by weakly electric fish., J. Comp. Physiol., 99, 103.118, 1975.

[15] Lissman, H. W., .On the function and evolution of electric organs in fish., J. Exp. Biol., 35, 456.486, 1958.

[16] Tareq H.Mezughi,Juhari Mat Akhir,Analytical Hierarchy process method for mapping Landslide Susceptibility to an Area alongthe E-W Highway, Asian Journal of Earth Sciences 5(1):13-24,2012 ISSN 1819-1886/DOI:IO.3923/aies.2012.13.24.

[17] P.samuel,A.Raja,'Investigation and Application of Marine Derived Microbial Enzymes: Status and prospects",International Journal of oceanography and marine Ecological system 1 (1) : 2012ISSN2224-9X/.ijomes.2012.1.10. 